Article

\title{
Structure of Moves in Research Article Abstracts in Applied Linguistics
}

\author{
Seden Can ${ }^{1}$, Erkan Karabacak ${ }^{1}$ and Jingjing Qin ${ }^{2, *}$ \\ 1 Department of English Language Teaching, College of Education, Yeditepe University, 26 Ağustos Yerleşimi, \\ İnönü Mah., Kayışdağı Cad., 34755 Istantul, Turkey; sedencan3277@yahoo.com (S.C.); \\ erkankarabacak@gmail.com (E.K.) \\ 2 Department of English and Writing Studies, Zayed University, P.O. Box 144534, Abu Dhabi, UAE \\ * Correspondence: jingjingqin79@gmail.com; Tel.: +971-50792-9676
}

Academic Editor: Yin Ling Cheung

Received: 3 May 2016; Accepted: 11 July 2016; Published: 18 July 2016

\begin{abstract}
An abstract summarizes the accompanying article in order to promote it. While many move-analysis studies of abstracts in applied linguistics $(\mathrm{AL})$ have used similar coding frameworks and demonstrated similar rhetorical organizations, their findings have not yet been aggregated to show the overall picture. The present study aimed to both examine move structures in AL abstracts and compare the results with previous studies both synchronically and diachronically. Fifty abstracts were collected from articles published in the journal English for Specific Purposes (ESP) between 2011 and 2013. Sentences were coded using a five-move scheme adapted from previous studies. Combining the results from previous research and the present study showed that most AL abstracts give information on the purpose, methodology, and findings of the associated article, while about half of the articles omit introduction of the topic and discussion of the findings. It was also found that authors frequently violate the move sequence expected by current schemes. These findings consistent with previous research suggest that future researchers informed by move analyses should explore the connection between the findings of move analyses and teaching materials for academic writing.
\end{abstract}

Keywords: move analysis; genre analysis; EAP; abstracts

\section{Introduction}

Swales [1] stated that the abstract is both a summary and a 'purified' reflection of the entire article, while Bhatia refers to the informative function of abstracts, claiming that they present "a faithful and accurate summary, which is representative of the whole article" [2] (p. 82). However, in addition to being informative, abstracts have a significant role in promoting research reports. Hyland [3], for example, maintains that it provides a decision making point for readers to judge whether the entire article merits further attention or not. Many academic writers therefore try to "persuade their readers to read the whole article by their effective selection of rhetorical features" [4] (p. 163). Martín-Martín notes that "abstracts constitute, after the paper's title, the reader's first encounter with the text", [5] (p. 5) pointing out that "there are few scholarly journals that do not require an abstract to be sent together with the original paper" [6] (p. 26). In general, unlike their accompanying articles, abstracts are freely available online, while many articles written in languages other than English also have English abstracts. Thus, being able to compose effective abstracts is critical for academic writers, and studying the language of abstracts is of significant value.

The literature also reveals that novice writers still have difficulty constructing well-structured abstracts that are appropriate to the norms set by their scientific community. For instance, Busch-Lauer found some linguistic and structural inadequacies in abstracts by Germans writing in English, which "may hamper the general readability for the scientific community" [7] (p. 769). Similarly, Ren and 
Li reported student writers" "incomplete appropriation to disciplinary practices" [4] (p. 165). Some student writers even had a "limitation" in their abstracts, which can be viewed as a sign of their insecurity or weakness as novice writers. Therefore, just like other sections of a research paper, studies regarding abstracts are required to raise novice writers' awareness by providing them with more rhetorical knowledge and guidelines to design better structured abstracts for their research articles.

One conventional method for examining language use, rhetoric, and text organization is move analysis. Moves are categories of functional roles in communication-in the present case, academic writing. For example, when writers express their ideas about what is missing in the previous literature, the purpose is probably to show that their study is going to fill this gap. Thus, we can identify these instances and mark them as gap-move. Previous studies have designed different move schemes for different sections of research articles in different fields. These schemes are composed of a number of moves and submoves (or steps). To illustrate, Stoller and Robinson [8] identified three major moves in methodology sections of research articles in the field of chemistry; namely, Move 1: Describe materials; Move 2: Describe experimental methods; and Move 3: Describe numerical methods. In addition to these major moves, they included two submoves for Move 2, namely procedures and instrumentation. These five categories were enough to tag the methodology sections of their sample of articles and analyze their rhetorical structures (for an informative summary on move analysis, see also Cortes [9], p. 35). Once a piece of text is tagged for moves, its rhetorical structure can be described, and comparisons with other texts can be made.

Previous studies have analyzed moves from four perspectives: range, amount, organization, and linguistic features. The majority of move-analysis studies have explored the issue of range (essentiality), or how necessary a move is. For example, they ask how many introduction sections out of one hundred contain background information about the study (background-move), or how many abstracts out of one hundred present the results (results-move). An arbitrary cut-off point is set to assign a category for each move; for example, if a move occurs in $60 \%$ or more of the particular section in different articles, then it can be labeled conventional, or if less, optional [10]. At the time of the present paper, eight studies had investigated the issue of essentiality in applied linguistics (AL) abstracts, using the same or comparable frameworks. Thus, in the present paper, we tabulate the results from these previous studies alongside with our findings to present the general picture.

Some studies also focused on amount (length) of moves in sections, for example, asking what percentage of texts on average is allocated for discussing the weaknesses of the study (limitation-move). The total can be calculated based on frequency counts of move-tags or the number of words within a move-tag. For example, Ren and Li [4] argued that the importance attached to a move is concomitant with the length devoted to it. One of their findings was that abstracts written by students in AL allotted more words to the introduction move, whereas abstracts from published research articles had more words in the results move. They interpreted this difference as indicating that deficiencies in student studies created insecurity about their results. However, most previous studies have ignored this important variable of amount (length) for moves. The present study also strives to fill this gap.

Because almost all studies emphasize a connection between move analyses and materials development for teaching, organization of move categories in a paper or section, how moves are sequenced, is also a critical part of move-analysis approaches. Salager-Meyer [11] (as cited in Hyland [12]) asserts that a well-structured abstract should involve all four structural units (introduction-methods-results-conclusions) in a linear order. But is this really so? Do they follow an order that is promoted by teaching materials or expected by schemes for move analyses? Where do writers locate suggestions for future studies in their discussions (future studies move)? Previous studies presented these organizational patterns in a non-systematic way, such as discussions of several patterns that are observed most frequently. The present study attempts to offer an innovative visual chart that visualizes move organization in the whole sample of 50 abstracts, as presented in the third section below. In addition, we undertake more systematic counts of move patterns. 
Lastly, again for the ultimate reason of developing teaching materials, many previous studies also examined certain lexical features. What kinds of grammar structures, vocabulary, tense, modals, formulaic expressions and similar other language features are used to realize these moves? For example, what kinds of verbs or terms do authors use when describing the statistics used in the study (numerical methods move)? Which tenses do authors use when describing procedures in methods sections (procedure-move)? To illustrate, Hyland and Tse, comparing abstracts written by novice and expert writers for use of the evaluative that in abstracts, showed that both novice and expert writers tend to use the that construction quite frequently "to mark their main argument, to summarize the purposes of the research and to express a stance on the reliability of the information presented" [13] (p. 137). However, analyzing linguistic features within each move category is beyond the scope of the present study.

In addition to descriptions, comparisons of the move features described above can be made between move types, native and non-native English (or novice and expert) users, between different languages, across disciplines, and different points in time. Studies comparing novice and expert writers include Amnuai and Wannaruk [14], Busch-Lauer [7], Ren and Li [4], Samar, Talebzadeh, Kiany, and Akbari [15], and Tseng [16]. To illustrate, using the framework of Hyland [12], Ren and Li [4] compared the essentiality of rhetorical moves in abstracts written by expert and novice writers, and found that while student writers include all five moves in their abstracts, experts often included only three of them, namely purpose-method-results, ignoring the introduction and discussion moves. They concluded that experts do this in order to emphasize the persuasive, rather than informative role of abstracts. The present study, however, does not distinguish between native and non-native writers, and accepts all writers as expert users since they are published in the English for Specific Purposes (ESP) Journal.

Other studies, such as Alharbi and Swales [17] and Martín-Martín [6], have focused on comparing text organization in English and other languages. For example, Martín-Martín [6] compared social sciences abstracts in English and Spanish. Based on his four-move scheme, he found that $86 \%$ of articles in English involved the results move but only 41\% in Spanish. In the present study, however, we only focused on AL abstracts in English.

Comparisons have also been made across disciplines, for example Ghasemi and Alavi [18], Hyland [12], Li and Pramoolsook [19], Pho [20], and Saeeaw and Tangkiengsirisin [21]. Min [22] compared the verb tenses of humanities and social sciences (HSS), and natural sciences and technology (NST) research abstracts. The results indicated that tense choices were not significantly different, with the present tense being most prevalent. In addition, both disciplines showed a clear preference for the present perfect tense when referring to more than a single study and for the past tense when expressing reference to the author's own study. As mentioned earlier, the present study focuses only on abstracts from AL research articles.

Some studies have investigated whether text organization changes diachronically, such as Hyland [12], Hyland [3], Okamura and Shaw [23], and the present paper. While the abstracts we selected do not represent diachronic data, through comparisons with previous studies, there is a diachronic dimension regarding essentiality.

There has been a considerable amount of research on language use in AL abstracts (e.g., $[4,12,16,20,21,24,25])$. However, no study has aggregated findings from previous studies into a readable table. The present study does this in the third section below.

The journal English for Specific Purposes (ESP) is highly regarded in the field of AL, providing a rich source of data for move analysis studies, which may mean that its writers are more conscious about the rhetorical organization of their articles. The present paper reports a study of the distribution and arrangement of move patterns in ESP journal abstracts published between 2011 and 2013. The current study sought to answer the following research questions:

What is the range of the moves in AL abstracts? That is, what percentage of abstracts contain the target move (essentiality of a move)?

What is the amount of moves with respect to other moves in AL abstracts? That is, how much space is allotted for each move in the abstract (length; percentage of data for each move-tag)? 
How are moves organized in AL abstracts? That is, how well do moves follow the typical order of introduction-methods-results-discussion (sequence, linearity)? What are the frequent move sequences (patterns)?

\section{Materials and Methods}

\subsection{Construction of the Corpus}

Fifty research articles were randomly selected from the ESP journal, with abstracts from recent issues published between 2011 and 2013 preferred to reflect current writing practices. Only abstracts were prepared for manual text analysis, discarding the title, information about authors, and keywords. The size of the corpus was limited to 50 research article abstracts, which can be regarded as sufficient to make reasonable generalizations and comparisons with previous studies. Table 1 presents descriptive statistics about the corpus size.

Table 1. Frequencies in the corpus for abstracts, words, sentences and their mean lengths.

\begin{tabular}{ccccc}
\hline $\begin{array}{c}\text { Number of } \\
\text { Abstracts }\end{array}$ & $\begin{array}{c}\text { Total Number } \\
\text { of Words }\end{array}$ & $\begin{array}{c}\text { Total Number of } \\
\text { Sentences }\end{array}$ & $\begin{array}{c}\text { Mean Length of Abstracts } \\
\text { in Terms of Words }\end{array}$ & $\begin{array}{c}\text { Mean Length of Abstracts } \\
\text { in Terms of Sentences }\end{array}$ \\
\hline 50 & 9074 & 343 & 181.41 & 6.86 \\
\hline
\end{tabular}

Word counts for each abstract were found using Microsoft Word (City, US State, Country) while the total number of sentences within the corpus was counted manually. The number of words in the abstracts ranged from 94 to 249 , which shows that the authors sampled in this study generally conformed to the ESP journal's guidelines for abstract writing in its Author Information Pack: "A concise and factual abstract is required (of between 100 and 200 words). The abstract should state briefly the purpose of the research, the principal results and major conclusions" ([26] on 1 July 2015). The number of sentences in the abstracts ranged from three to 11 sentences.

\subsection{Coding the Abstracts for Moves}

To code the moves in the abstracts, Pho's [20] move framework, which was adapted from Dos Santos's [24] and Hyland's [12] five-move pattern, was applied after making slight changes in one of the moves. Table 2 illustrates the modified version of Pho [20], who introduced a set of questions and functions for more practical coding of moves in abstracts (see Li \& Pramoolsook [19] for the evolution of the five-move scheme for AL abstracts).

Table 2. Framework for move coding in the current study, adapted from Pho [20].

\begin{tabular}{llll}
\hline \multicolumn{1}{c}{ Abstract Moves (Pho [20]) } & \multicolumn{1}{c}{ Function/Description } & Question Asked & $\begin{array}{c}\text { Move Labels along with } \\
\text { Abbreviations in the } \\
\text { Present Study }\end{array}$ \\
\hline Situating the research & setting the scene for the current research & What is known in the field? & introduction (I) \\
\hline Presenting the research & $\begin{array}{l}\text { stating the purpose of the study, } \\
\text { research questions and hypotheses }\end{array}$ & What is the study about? & purpose (P) \\
\hline Describing the methodology & $\begin{array}{l}\text { describing the materials, subjects, } \\
\text { variables, procedures, etc. }\end{array}$ & How was the research done? & methods (M) \\
\hline Summarizing the findings & reporting the main findings of the study & $\begin{array}{l}\text { What did the researcher } \\
\text { find? }\end{array}$ & results (R) \\
\hline Discussing the research & \multicolumn{2}{l}{ interpreting the results/findings } \\
and/or giving recommendations & What do the results mean? & discussion (D-a) \\
\hline (a) & no discussions or recommendations & & pseudo-discussion (D-b) \\
\hline
\end{tabular}

This framework seems also suitable for the present study due to the fine distinctions made between each move. We avoided numbering the moves in order to avoid confusion and the misperception that 
one move has to follow another move. For this reason, the more transparent and short abbreviations, I, $\mathrm{P}, \mathrm{M}, \mathrm{R}, \mathrm{D}-\mathrm{a}$, and D-b, are used to represent each move, as shown in the right-hand column in Table 2. One new function had to be added to the framework as we observed that there were both sentences in the abstracts interpreting the findings and giving recommendations and sentences giving no reflection of the discussion of the research. In other words, in some discussion moves in the present sample, the results were not interpreted. Instead, the abstract simply stated that discussion, implications, and/or recommendations are presented further in the paper. We named this submove "pseudo-discussion". For this reason, we divided the last move in the framework into two submoves: one reflecting the content of the discussion, $D-a$; and one mentioning the discussion without presenting its content, $D-b$. The following two examples illustrate this important difference between them:

$<D-a>$ It argues that this approach need not be restricted to small groups of well-resourced students, but can be implemented in mainstream EAP classes.

$<D-b>$ The article concludes by outlining the pedagogical implications of the findings from an ESP perspective.

The numbers preceded by a hash symbol represent articles used in the present study.

The unit of coding in our study was the sentence. However, in those cases when a sentence contained more than a single move, we tagged clauses or phrases. Each sentence $(n=343)$ in the abstracts was analyzed manually to identify the moves contained in it. To test for inter-rater reliability, three other researchers were asked to identify the moves, with $10 \%$ of the corpus randomly assigned to each coder (five out of 50 abstracts). The analysis of each coder was then compared to the researcher's, yielding values of Cohen's kappa of $0.86,0.82$, and 0.86 , which indicates a high level of agreement.

In an attempt to visualize the whole corpus diagramatically, we assigned shades of gray for each move in a manner that reflects the expected order of I-P-M-R-D. Figure 1 shows the abbreviations and the corresponding gray codes, which are used in Figure 2 in the following section.

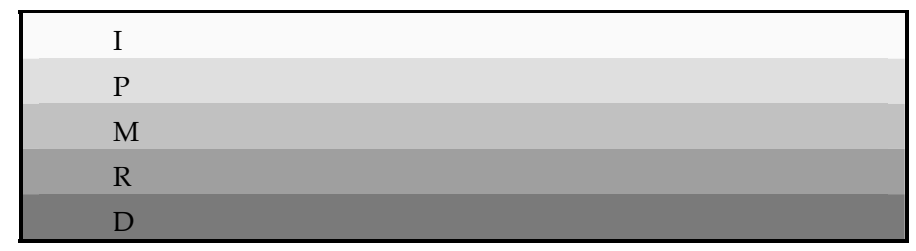

Figure 1. Moves and corresponding gray tones.

\subsection{Analyzing Range, Amount, and Organization}

Regarding range (essentiality), the cut-off points suggested by Kanoksilapatham [10] and Pho [20] were used. Although undeterminable these cut-off points seem, we adapted them for the sake of comparability. First, the percentage of abstracts that contain each move was calculated to determine their essentialities. If a move existed in $60 \%$ or more of the abstracts, it was labeled "conventional", and if it existed in 59\% or less, we labeled it "optional".

To measure amount, after tagging each sentence for a move or moves it contains, we found the percentages for each move in the whole tags. In other words, tag frequency is used to measure the amount for the corresponding move. This computation was different from the one for range in that it showed how much space is allotted for each move in the abstracts.

Organization of the moves in an abstract was evaluated by two methods. First, we examined the chart created to visualize the whole dataset. Second, we counted all move sequences and examined the data through frequencies. In the case of the chart, after every move in the data had been hand-coded, a 
program was written to read the hand-coded data and assign each code its corresponding grey tone as illustrated above in Figure 1. The resulting chart was composed of lines, each of which represented one abstract. In addition, on each line, move-tags were represented by rectangles. Although the number of moves in each abstract varied, the program equalized the lengths of each line (abstract) by using percentages.

As for the second method, we merged all consecutive moves that were the same to create a list of move patterns representing each abstract. We categorized patterns that followed the expected order as linear, and ones that violated it as non-linear. Frequencies of the pattern-types were counted and examined. Move pattern types were analyzed both as long move sequences at the abstract level and as frequently occurring shorter move sequences: in our case, within a length of four move tags.

Move embedding was also part of organization. The hand-tagged data was re-examined sentence by sentence to identify those involving more than a single move. Sentences were categorized into two-move embedding and three-move embedding categories, with three-move embedding being the maximum found. Frequencies were counted and the types of combinations were identified.

\section{Results and Discussions}

This section discusses the findings regarding range, amount, and organization of the five moves and two submoves.

\subsection{Range of the Moves}

Only 17 (34\%) of the abstracts contained all five move types, although Hyland [12] found an even a lower percentage (5\%) from various fields. The number of abstracts lacking at least one move was 33 $(66 \%)$. In this section, we report both our findings and the ones by eight previous studies in Table 3, at around nine different time points diachronically sequenced between 1980 and 2013. We discuss level of essentiality for each move type. In other words, how necessary are these five moves? Comparisons are made between the present study and the average of the nine studies, including the present study.

The most frequent category in the present study was M, which was present in $100 \%$ of the abstracts. Although Tseng [16] also found this move to be the most frequent, the average from all nine studies $(80 \%)$ shows that $\mathrm{M}$ is only the third most frequent move, after $\mathrm{R}(93 \%)$ and $\mathrm{P}(91 \%)$. However, two of the lowest percentages for M come from Hyland's [12] study. As also pointed out by Pho [20]), we are not sure whether some of the abstracts in Hyland [12] came from theoretical articles, which typically do not have a methodology section. Overall, the results indicate that $\mathrm{M}$ is a conventional move in AL articles.

The second most frequent move in our sample was $\mathrm{P}$ at (96\%). As Table 3 shows, $\mathrm{P}$ was the second most frequent move (91\%) found by previous studies. In fact, in six of the nine studies, this move occurred in more than $90 \%$ of the abstracts. This high percentage indicates that $\mathrm{P}$ is also a conventional move for AL writers.

$\mathrm{R}$ was the third most frequent in the present study at $92 \%$. The average of the nine studies (including the present study) showed that this move occurred in abstracts with the highest percentage at $93 \%$ (see Table 3). In seven of the nine studies listed in Table 3, R occurred in more than $90 \%$ of the abstracts. Thus, $\mathrm{R}$ is also a conventional move when writing an AL abstract.

Abstracts are highly condensed, so the high frequencies of $\mathrm{M}, \mathrm{P}$, and $\mathrm{R}$ indicate the importance attached to them by AL authors. That particular prominence is given to these three moves may also result from the authors' desire to promote their studies. That is, they believe that, because readers expect the abstract to explain their purposes, describe the methodology, and report the results, including these three moves will increase the chances of getting their article read. 
Table 3. Comparison of the move analysis results by the present and previous studies on applied linguistics abstracts.

\begin{tabular}{|c|c|c|c|c|c|c|c|c|}
\hline Author & Source & Year & Scheme & I & $\mathbf{P}$ & $\mathbf{M}$ & $\mathbf{R}$ & D \\
\hline & $\begin{array}{l}\text { - Number of applied linguistics abstracts } \\
\text { - Journals } \\
\text { - Type of article (primary or not) }\end{array}$ & (Data) & & Introduction (\%) & Purpose (\%) & Method (\%) & Results (\%) & Discussion (\%) \\
\hline \multirow[t]{2}{*}{ Hyland (2004) } & $\begin{array}{l}\text { - } 30 \\
\text { - TQ, JP } \\
\text { - unknown }\end{array}$ & 1980 & Hyland (2000) & 40 & 70 & 47 & 96 & 1 \\
\hline & $\begin{array}{l}\text { - } 94 \\
\text { - unknown } \\
\text { - unknown }\end{array}$ & unk. & Dos Santos (1996) & 43 & 99 & 98 & 80 & 53 \\
\hline Hyland (2004) & $\begin{array}{l}\text { - } 200 \\
\text { - AL, ESP, IJAL, JP, SLR, SLW, SYS, TQ, WC, WE } \\
\text { - unknown }\end{array}$ & 1997 & Hyland (2000) & 46 & 87 & 42 & 96 & 19 \\
\hline \multirow[t]{5}{*}{ Pho (2008) } & $\begin{array}{l}\text { - } 20 \\
\text { - MLJ, TQ } \\
\text { - primary }\end{array}$ & 2005-2006 & Dos Santos (1996) & 45 & 100 & 100 & 100 & 80 \\
\hline & $\begin{array}{l}\text { - } 90 \\
\text { - AL, LL, TQ } \\
\text { •primary }\end{array}$ & 2005-2007 & $\begin{array}{c}\text { Swales and Feak (2004), } \\
\text { Dos Santos (1996) }\end{array}$ & 41 & 96 & 97 & 91 & 74 \\
\hline & $\begin{array}{l}\text { - } 25 \\
\text { - unknown } 5 \text { leading journals } \\
\text { - unknown }\end{array}$ & 2007 & Hyland (2000) & 60 & 96 & 60 & 100 & 52 \\
\hline & $\begin{array}{l}\text { - } 100 \\
\text { - AL, ESP, SYS } \\
\text { - primary }\end{array}$ & 2009-2012 & Hyland (2000) & 44 & 83 & 86 & 87 & 69 \\
\hline & $\begin{array}{l}\text { - } 100 \\
\text { - AL, ESP, SYS, TQ } \\
\text { - primary }\end{array}$ & 2010-2013 & Hyland (2000) & 54 & 94 & 91 & 95 & 72 \\
\hline The present study & $\begin{array}{l}\cdot 50 \\
\bullet \text { ESP } \\
\cdot \text { primary }\end{array}$ & 2011-2013 & Pho (2008) & 54 & 96 & 100 & 92 & $\begin{array}{c}84 \\
(50+34)\end{array}$ \\
\hline Average & - & - & - & 47.45 & 91.23 & 80.12 & 93.00 & 56.00 \\
\hline
\end{tabular}


The D move, the last move in our framework, was the fourth most frequent category. Of the 50 abstracts, $84 \%$ included this move. In contrast, as seen in Table 3, only $56 \%$ of abstracts from all nine studies had this move. Again, this may be because two of the percentages from Hyland [12] are disproportionately low, 1\% in 1980 and 19\% in 1997. Although Hyland [12] interpreted these two values as indicating a diachronic change due to abstracts becoming more informative, Table 3 shows no such pattern for the nine studies in general. However, it may be possible that this sudden change occurred from the 1980s to the 1990s before stopping later. Thus, the question of diachronic change in move essentiality of abstracts may need further investigation. When the 1980's result is ignored in Table 3, the average for D jumps to 63\%, qualifying it as 'conventional'. As reported above, this move is clearly expected by the ESP journal's guidelines for authors, as it specifically asks them to state their "major conclusions".

As explained earlier, our scheme also distinguished between the two realizations of D: D-a and D-b. D-a was an informative discussion move, whereas D-b is what we have called a 'pseudo-discussion'. To our surprise, no previous study has reported these two distinct submoves in abstract conclusions, yet submove D-a occurred in 50\% of the abstracts we sampled, and D-b in 34\%. Thus, while we suggest that $\mathrm{D}$ seems conventional, $34 \%$ of the authors avoid informative discussion as seen in the following two examples:

$<D-b>$ The paper closes with advice, based on the corpus analysis and findings, for engineering researchers concerning manuscript preparation, as well as advice on pedagogy for teachers of engineering communication.

$<D-b>$ This study has pedagogical implications for the writing practices of native and non-native researchers and contributes to the widening of current research on the genre of the $R A$.

Given that more than a third of the abstracts in the present study had this pseudo-discussion move, we believe it deserves further investigation. When authors signal that there is valuable information in the article but do not reveal any details about the content, this may hint at a tactical decision on their part to enhance the promotional aspect of the abstract.

The least frequent move in the present study was I, at $54 \%$. The same move was also the least frequent in the average of the nine studies, at $47 \%$. In fact, in eight out of nine studies, this move occurred in less than $60 \%$ of the abstracts (see Table 4 ). It seems then that this is the only move that is truly 'optional'.

Table 4. Number and percentage of abstracts with five moves in the present study $(n=50)$.

\begin{tabular}{cccc}
\hline Move & $\boldsymbol{n}$ & $\mathbf{\%}$ & Essentiality \\
\hline $\mathrm{I}$ & 27 & 54 & Optional \\
$\mathrm{P}$ & 48 & 96 & Conventional \\
$\mathrm{M}$ & 50 & 100 & Conventional \\
$\mathrm{R}$ & 46 & 92 & Conventional \\
$\mathrm{D}$ & 42 & 84 & Conventional \\
$\mathrm{D}-\mathrm{a}$ & 25 & 50 & N/A \\
$\mathrm{D}-\mathrm{b}$ & 17 & 34 & N/A \\
\hline
\end{tabular}

In summary, the most essential three moves in ESP abstracts are P (presenting the research purpose), $\mathrm{M}$ (describing the methodology), and R (summarizing the findings). Except for Hyland's [12] abstracts from 1997, all studies found that these three moves had the broadest range out of the five. The last row of Table 4 displays the average of the percentages. Abstracts mostly tend to include information about purpose, methodology, and results (more than 80\%). Based on the cut-off points we established, all of 
these three most frequent moves can be categorized as 'conventional' for AL abstracts (higher than $60 \%$ ). We also suggest that the discussion move may also be conventional, albeit with an option for writers to hide the content. However, caution should be exercised here in terms of interpreting the patterns found in this section, as variation exists regarding the corpus size, journal source, and article type among the studies reviewed above.

\subsection{Amount of Moves in the Whole Corpus}

Figure 2 shows the percentages of each move in 388 move-tags. M comprised 35\% of the tags, which is the highest among the five moves, suggesting that the focus of the ESP journal abstracts was on the methodology, even though the ESP style guide makes no mention of methods for the abstract. $\mathrm{R}$ and P occurred 89 (26\%) and 70 (20\%) times, respectively, indicating that most authors of ESP Journal not only use these three moves but also allocate considerable text space for them.

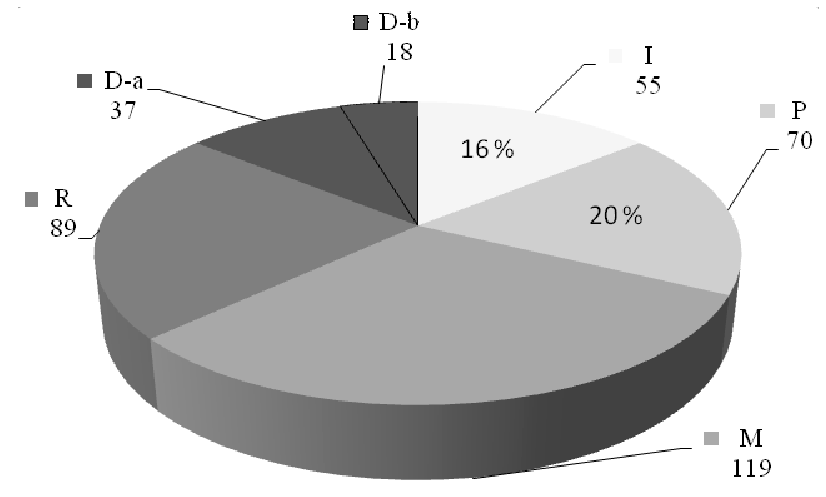

Figure 2. Frequency of occurrence and distribution of moves at sentence level.

By contrast, both I and D had the lowest percentage, at $16 \%$ each. In summary, when we order the moves regarding large to small space allotted to them, the order is $\mathrm{M}, \mathrm{R}, \mathrm{P}$, and I and D. Ren and $\mathrm{Li}$ [4], which is the only previous study that examined amount, reported the order as R, I, M, P, and D. Thus, D had the smallest quantity in both studies. However, the present paper also found I to have the smallest allocation, whereas it was the second largest in Ren and Li's report. The quantity of $\mathrm{M}$ in Ren and Li was in the middle, whereas we found it to have the largest portion. Future studies need to pay more attention to this move feature, which we named amount. The submoves of D, D-a and D-b (pseudo-discussion), occurred 37 (11\%) and 18 (5\%) times, respectively. However, these low percentages do not necessarily indicate that these submoves play a negligible role. For example, as argued in the following section, although D-b only comprises $5 \%$ of the present dataset, it has a quite broad range, indicating a calculated use on the part of the writers.

Although we counted move-tags to find their amount in the whole dataset, tags are also composed of different numbers of words. A more precise length measurement may be needed, perhaps involving word counts under each move-tag [4], which was beyond the scope of the present study.

\subsection{Organization of Moves (Sequence, Linearity)}

Schemes used in move analyses clearly indicate a linear expectation so analyzing the order of the moves is warranted to expose the organization of abstracts. Based on the discussion in the previous two sections, it is clear that moves exist with varying amounts (including zero) in abstracts. In this section, we discuss how well these five moves follow a linear order, rather than just discussing the existence or quantity of moves. In Figure 3, each line represents a single abstract. For easy reference, we use identification numbers for abstracts as seen in the first column. Each rectangle represents a move-tag, which is presented inside the rectangle. Because the token counts of moves in each abstract were different, percentage values are used to make each line of equal length, thus the sizes of rectangles 
are not indicative of any variable and should be ignored. As mentioned in the methods section above, a light gray to dark gray tone is assigned to each move, to visually reflect the expected sequence.

From a distance, Figure 3 displays a clear progression from light to dark gray. Thus, the overall pattern supports the presumption of a linear structure made by all move analysis schemes and many teaching materials. However, at the same time, a more careful look reveals many breaches of this linearity.

In order to measure linearity, all consecutive move-tags from the same category were merged, i.e., if there are three $\mathrm{M}$ moves in a row, we marked them as one.

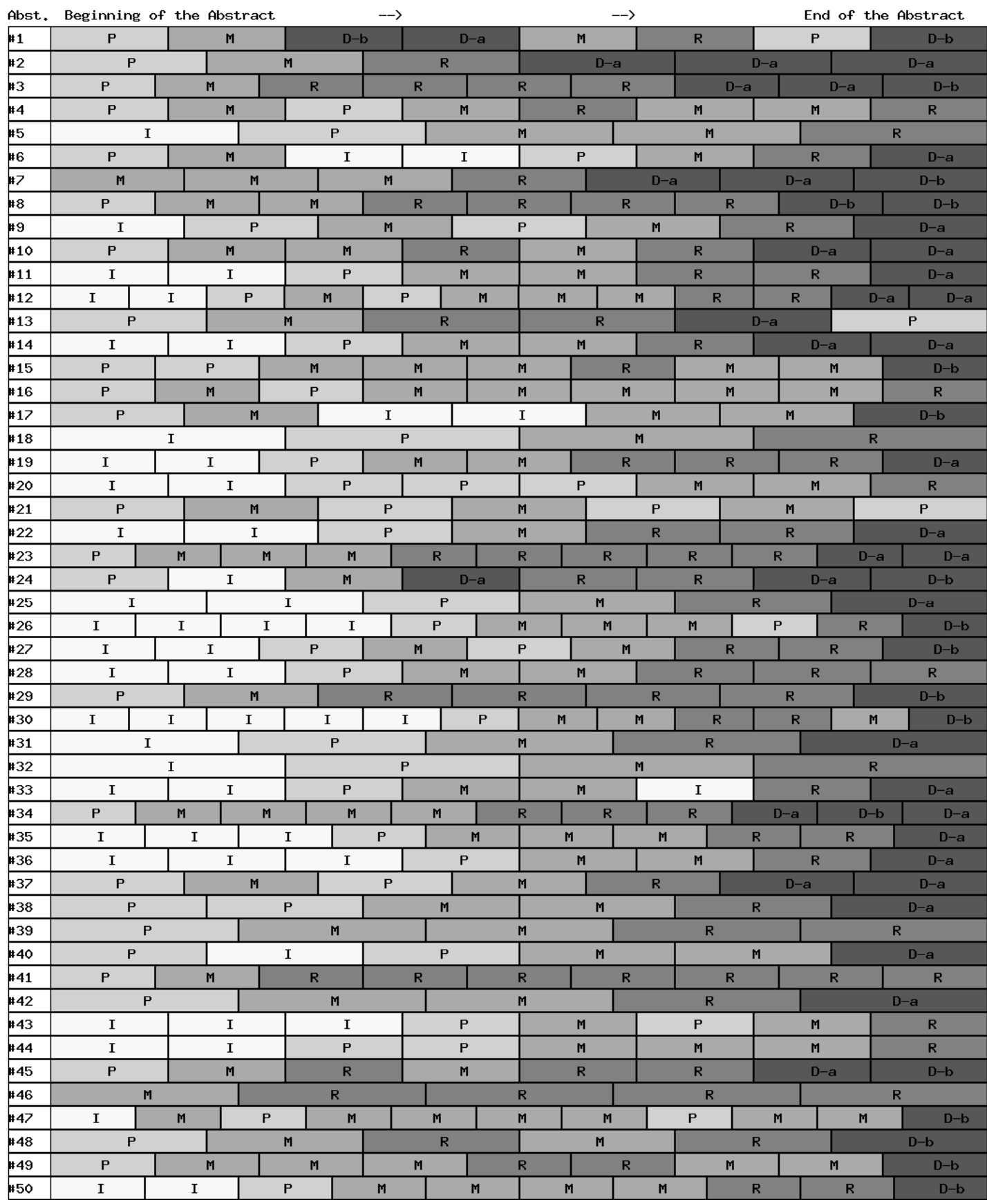

Figure 3. This chart visualizes the data as a whole. Each line represents one of the 50 abstracts examined. As indicated by the arrows at the top, the first rectangle on the left is the first move, and the last rectangle on the right is the last move in the corresponding abstract. Note. This visual was prepared using Perl programming language and its GD Graphics Module Version-2.56 by Lincoln D. Stein. 


\subsubsection{Completely Linear Patterns}

A perfectly linear abstract would contain all five moves and sequence them according to the expected order: I, P, M, R, and D (introduction, purpose, method, results, and discussion, respectively). The number of linear articles containing all five moves in the expected order was 9 out of 50 (18\%) (see abstracts \#11, \#14,\#19,\#22, \#25, \#31, \#35, \#36, and \#50 in Figure 3). The following abstract illustrates a linear move sequence:

$<I>$ Email has revolutionised the way in which professionals work and companies operate, and yet has received surprisingly little scholarly attention in English for Specific Purposes and has an unexpectedly muted presence in many Business English textbooks. $<I>$ The dearth of research into email use in globalised business settings may be one of the factors behind the unnecessarily wide gulf that separates the office and the classroom. $\langle P>$ This article seeks to narrow this gap by making practical suggestions about the design of email tasks for use in Business English courses. $<M>$ These ideas are based on three complementary sets of qualitative data derived from Hong Kong's service sector: over 30 h of interviews with English-using Chinese professionals, four "week-in-the-life" case studies and 50 email chains comprising 406 separate messages. $<R>$ These data provide pedagogically relevant information about the function of email in internal and external communication, its intimate relationship with spoken communication, the importance of intertextuality in email chains and the length, language and structure of email messages. $<D-a>$ The study recommends the adoption of a simulation-based approach in which email communication is embedded in a series of interdependent activities that integrate speaking, listening, reading and writing.

\subsubsection{Semi-Linear Patterns}

Some abstracts were composed of fewer than the five move types, yet followed the expected linearity. We called these abstracts semi-linear. There were 18 semi-linear abstracts (36\%), namely \#2, $\# 3, \# 5, \# 8, \# 7, \# 18, \# 20, \# 23, \# 28, \# 29, \# 32, \# 34, \# 38, \# 39, \# 41, \# 42, \# 44$, and \#46. Most of these abstracts omitted I and/or D. Thus, in total, 27 of the abstracts (54\%) were linear. Table 5 shows the six patterns observed along with their frequencies.

Table 5. Frequencies and percentages of linear and semi-linear patterns in 27 abstracts.

\begin{tabular}{cccccccc}
\hline Linearity & \multicolumn{4}{c}{ Moves } & & Frequency & Percentage of Abstracts \\
\hline Linear & I & P & M & R & D & 9 & 18 \\
Semi-linear & - & P & M & R & D & 8 & 16 \\
Semi-linear & I & P & M & R & - & 6 & 12 \\
Semi-linear & - & P & M & R & - & 2 & 4 \\
Semi-linear & - & - & M & R & D & 1 & 2 \\
Semi-linear & - & - & M & R & - & 1 & 2 \\
\hline
\end{tabular}

The most frequent linear pattern in Table 6 was the expected I-P-M-R-D sequence, which was followed by $18 \%$ of the abstracts. [21] observed a slightly different order, finding P-M-R-D to be the most frequent, followed by I-P-M-R-D. However, the top two move patterns in our observations are as reported by [25], who also found P-M-R to be the third most widely used pattern and I-P-M-R to be the fourth. However, this was reversed in our data. While these slight differences in rank order seem negligible, it is not clear how these studies dealt with nonlinear patterns, as discussed in the following section.

\subsubsection{Non-Linear Patterns}

A 'non-linear' abstract was composed of moves that did not follow the expected order in the frameworks used by the present paper and many previous studies. Out of the 50 abstracts, 23 were 
non-linear (46\%), as can easily be spotted in Figure 2 from lapses in the general pattern of lighter to darker tones of gray. Eight of these 23 abstracts contained all five-move-types, while 15 lacked at least one. The following is an excerpt from abstract \#24, illustrating a non-linear order:

$<P>$ This paper presents a comprehensive overview of lexicogrammatical devices which highlight important or relevant points in lectures. $<I>$ Despite the established usefulness of discourse organizational cues for lecture comprehension and note-taking, very little is known about the marking of relevance in this genre. $<M>$ The current overview of lexicogrammatical relevance markers combines a qualitative and quantitative investigation of 160 lectures from the British Academic Spoken English (BASE) corpus. [ ... ]

Abstract \#24 presents the purpose up-front before situating the study by giving some background information on the topic. The frequency of these non-linear move patterns raises questions about Salager-Meyer's [11] claim that for an abstract to be well structured, it is necessary that the moves are sequenced in one logically linear order (I-M-R-D, or in our case I-P-M-R-D).

In addition, it seems that these non-linear patterns are not used arbitrarily since recursion or changing the order of a move may execute a communicative function intended by the author. Whereas Table 5 can easily summarize and align the linear pattern types, there are 18 non-linear patterns, only four of which are repeated, as seen in Table 7.

Table 6. Frequencies of 23 non-linear move patterns.

\begin{tabular}{llll}
\hline \multicolumn{2}{l}{ Repeated Nonlinear Move Sequences } & \multicolumn{2}{l}{ Nonlinear Move Sequences Occurred Once } \\
\hline & Frequency & & \\
PMRMRD & 3 & IMPMRMD & PMDMRPD \\
IPMPMRD & 2 & IPMIRD & PMIMD \\
PMPMRD & 2 & IPMPMR & PMIPMRD \\
PMRMD & 2 & IPMPRD & PMPMPMP \\
& & IPMRMD & PMPMR \\
& PIMDRD & PMPMRMR \\
& PIPMR & PMRDP \\
\hline
\end{tabular}

Table 6 lists the patterns that occur in the whole of each abstract; however, recursive patterns are harder to discern visually. With the help of a concordancer, we counted the most frequent four-move-sequences, since a shorter sequence would not have revealed the cyclical pattern, and only looked at patterns that occurred four or more times. Table 6 shows that the most frequent cyclical pattern was P-M-P-M, which occurred nine times in seven abstracts. The first explanation that comes to mind is that if there are two purposes, there will be two methods; however, this was never observed. All occurrences of this pattern indicated that when authors wanted to give detailed information about their purposes and methodology, they embedded these two moves in two or more sentences. The following excerpt follows the P-M-P-M pattern.

$<P>$ This paper reports the findings of a study aiming to reveal the recurring patterns of lexical, syntactic and textual errors in student translations of a specialized EU genre from English into Hungarian. $<M>B y$ comparing the student translations to the official translation of the text, $<P>$ this article uncovers the most frequent errors that students made and links these errors to the elements of translation competence. $\langle M>$ In order to achieve these goals, textual analysis and retrospective interviews were used. [...]

Three other patterns, M-P-M-R, P-M-R-M, and M-R-M-D, had the same cause; that is, authors wanted to give detailed information about the methodology. Thus, we can conclude that $\mathrm{M}$ is the most 
frequently recycled move, followed by $\mathrm{P}$. The following excerpt illustrates the P-M-R-M pattern and shows how $\mathrm{M}$ iterates several times.

$<P>[\ldots]<M>$ enrolled in a professional forestry program. $<P>$ Specifically, the study identifies the contribution of a concordance program in highlighting the characteristics of effective writing in the field of forestry $<M>b y$ focusing on a set of selected linguistic features: (a) linking adverbials, (b) reporting verbs, (c) verb tenses (past and present), and (d) passive sentence structures. $<M>$ These features were selected for the study based on a comparison of a corpus of published forestry articles vis-à-vis a corpus of students' research reports. $<R>$ Initial analysis showed interesting differences in the distributions of these linguistic features between professional and student texts. $<M>[\ldots]$ $<M>[\ldots]<R>[\ldots]$

Table 7. Four move sequences that occur four or more times in 23 non-linear abstracts.

\begin{tabular}{cc}
\hline Move Sequences & Frequency \\
\hline P M P & 9 \\
M P M & 8 \\
P M M & 8 \\
M R D & 4 \\
\hline
\end{tabular}

\subsubsection{Opening and Closing Sentences}

The first and the last sentences of abstracts should also be discussed as part of linearity. Only three moves ever appeared in the first sentences: P (50\%), I (46\%), and M (4\%). Hyland [12] explains that writers in the "soft knowledge domains", such as AL, introduce the topic, whereas writers in "hard knowledge fields" emphasize the methodology more. Our findings supported his idea by showing that, in the first sentence position, introduction is the second most frequent move. However, almost half of abstract writers preferred to start their abstracts by stating the purpose of their research. No abstract opened with R or D. Table 7 presents the distribution of opening and closing sentences. It shows that researchers tended to embed only $\mathrm{P}$ and $\mathrm{M}$ in the very first sentence of their abstracts. As an opening sentence, $\mathrm{M}$ occurred alone in only two of the abstracts.

Table 8. Distribution of opening and closing sentences $(n=50)$.

\begin{tabular}{lcccc}
\hline \multicolumn{2}{c}{ Opening Sentences } & \multicolumn{2}{c}{ Closing Sentences } \\
\hline \multicolumn{2}{c}{ Frequency } & $\%$ & Frequency & $\%$ \\
\hline I & 23 & 46 & 0 & 0 \\
P & 25 & 50 & 2 & 4 \\
M & 2 & 4 & 0 & 0 \\
R & 0 & 0 & 12 & 24 \\
D & 0 & 0 & 36 & 72 \\
D-a & 0 & 0 & 20 & 40 \\
D-b & 0 & 0 & 16 & 32 \\
\hline
\end{tabular}

Regarding the last sentence, Table 8 shows that $72 \%$ of the abstracts closed with $\mathrm{D}$, which is almost identical with Tseng's [16] finding of 74\%. We found submoves D-a in 40\%, and D-b in 32\% of final sentences. Hyland [12] (p. 84) argues that introduction and conclusion sections are "essentially persuasive". Although only 5\% of the moves were D-b in the whole dataset, the high percentage (32\%) in the last sentence position supports Hyland [12] and our earlier suggestion that D-b is a tactical choice to persuade the reader to read the article, in addition to its likely function of truncating discussion to help meet length limitations. The $\mathrm{R}$ move occurred in $24 \%$ of final sentences, which was again similar 
to Tseng's $22 \%$. Only two of the last sentences (4\%) P and none with I or M, which are is also very similar to Tseng's findings.

\subsubsection{Move Embedding}

As mentioned earlier, there were 388 moves in 343 sentences due to some sentences containing more than one move, or move-embedding. The number of sentences that incorporated more than one move is $46(13 \%)$. The observed combinations were $\mathrm{P}+\mathrm{M}, \mathrm{M}+\mathrm{R}, \mathrm{R}+\mathrm{D}$, and $\mathrm{I}+\mathrm{P}+\mathrm{M}$ in 36 sentences $(10.5 \%)$, seven $(2 \%)$, two $(0.5 \%)$ and one $(0.2 \%)$, respectively. The following excerpt shows how $\mathrm{P}$ and $\mathrm{M}$ are combined in a single sentence.

[ ... $]<P>$ It (the study) examines graduate learners' approaches to "examine-and-report-back" genre-analysis tasks $<M>$ by comparing 32 students from four disciplines: archaeology, history, literature, and media studies. [...]

The following excerpt shows how I, P, and M are combined in a single sentence with some overlap between $\mathrm{P}$ and $\mathrm{M}$.

$[\ldots]<I>$ Starting from the premise that tertiary sector ESP students may have more in common than their choice of discipline, $\langle M>$ this study uses interviews and questionnaires $\langle P>$ to investigate first and fourth year business students' beliefs about effective language learning. [ ... ]

Percentages of abstracts containing these move patterns $(\mathrm{P}+\mathrm{M}, \mathrm{M}+\mathrm{R}, \mathrm{R}+\mathrm{D}$, and $\mathrm{I}+\mathrm{P}+\mathrm{M})$ are, respectively, $58 \%, 14 \%, 4 \%$, and $2 \%$. Thus, it is clear that ' $\mathrm{P}+\mathrm{M}^{\prime}$ ' is the most commonly found embedding. Previous studies also found $\mathrm{M}$ to be the most frequently embedded move, especially with $\mathrm{P}$ or $R$ ([19-21,24,25]). This combining of closely related procedures within sentences seems to help writers not only save space but also create greater cohesion.

\section{Conclusions}

Although this study examined the move structures of 50 abstracts from a single AL journal, ESP, results were consistent with previous studies using data from a variety of AL journals. Thus, despite this relevant limitation in journal variety, our data seems representative of the language of AL abstracts. While space constraints prevented us from discussing the key linguistic structures within these moves, we believe linguistic realizations of moves deserve a separate detailed discussion using a much larger corpus than the ones in the present and previous studies.

The findings of the present and previous studies show that authors discuss results, purpose, and methodology in their abstracts more than implications of the findings or background information. Authors are well aware of the fact that they need to use the allowed space economically. Background information about the topic is the first to be omitted by writers in $\mathrm{AL}$, and thus it seems to be the only move in the optional category, being disregarded in more than half of the sampled abstracts. Overall, purpose, methodology, results, and implications of results are conventional, appearing in most AL abstracts. However, many writers avoid an informative discussion of their results. This frugality in interpreting the outcome of their studies not only allows them to save space but may also enable them to stimulate curiosity in the reader.

Writers in AL follow the typical introduction-(purpose)-methods-results-discussion order but with many deviations. For example, although the background move occurs in less than half of the abstracts, it is the most frequent move in the first sentence. Similarly, while closing the abstracts, writers mostly preferred discussing the implications of their findings. Thus, more than half of the abstracts follow a linear order, even if there are omissions of moves, while others do not follow the order due to iteration or deviant locations of moves. 
AL writers often combine the methodology with the purpose or results of their study within the same sentence. It is no surprise that the methodology move also takes the largest space in abstracts. The strategy of combining moves in a single sentence probably prevents choppiness and helps force more information into an inherently limited space.

As noted, the findings of the present study are consistent with the majority of previous studies in this line of inquiry. These congruous findings of move organizations and linguistic realizations could be of great use to teach novice writers how to write an abstract. Future studies should make this connection between the findings of move analyses and teaching materials for academic writing. Consequently, studying the effects of data-informed teaching materials on novice writers is another important research avenue. To this end, a larger corpus of move-tagged abstracts seems necessary to understand linguistic structures related to moves in abstracts that are sufficient to create teaching materials. However, move annotation is a labor-intensive undertaking so automatizing it is vital. One such attempt is a move-tagging software program named AntMover [27] (Version 1.0.0, Waseda University, Tokyo, Japan), although it is yet to be effectively utilized in move analyses; i.e., no studies cited in this paper used it. For such an automatic move-coding program to be realized, it is vital to compile hand-coded training materials with a standardized scheme, which requires co-operation between researchers doing hand-analysis and software developers.

Acknowledgments: We would like to thank Jerry Spring for his careful editing of the paper. We are responsible for all the errors that may remain.

Author Contributions: Seden Can and Erkan Karabacak contributed to the data coding and analysis; Erkan Karabacak and Jingjing Qin are responsible for proposing the study and constructing this research report.

Conflicts of Interest: The authors declare no conflict of interest.

\section{References}

1. Swales, J.M. Genre Analysis; Cambridge University Press: Cambridge, UK, 1990.

2. Bhatia, V.K. Analyzing Genre: Language Use in Professional Settings; Longman Publishing: New York, NY, USA, 1993.

3. Hyland, K. Teaching and Researching Writing, 2nd ed.; Routlege: Abingdon, UK, 2009.

4. Ren, H.; Li, Y. A comparison study on the rhetorical moves of abstracts in published research articles and master's foreign-language theses. Engl. Lang. Teach. 2011, 4, 162-166. [CrossRef]

5. Martín-Martín, P. The Rhetoric of the Abstract in English and Spanish Scientific Discourse: A Cross-Cultural Genre-Analytic Approach; Peter Lang: Bern, Switzerland, 2005.

6. Martín-Martín, P. A genre analysis of English and Spanish research paper abstracts in experimental social sciences. Engl. Specif. Purp. 2003, 22, 25-43. [CrossRef]

7. Busch-Lauer, I.A. Abstracts in German medical journals: A linguistic analysis. Inf. Process. Manag. 1995, 31, 769-776. [CrossRef]

8. Stoller, F.L.; Robinson, M.S. Chemistry journal articles: An interdisciplinary approach to move analysis with pedagogical aims. Engl. Specif. Purp. 2013, 32, 45-57. [CrossRef]

9. Cortes, V. The purpose of this study is to: Connecting lexical bundles and moves in research article introductions. J. Engl. Acad. Purp. 2013, 12, 33-43. [CrossRef]

10. Kanoksilapatham, B. Rhetorical structure of biochemistry research articles. Engl. Specif. Purp. 2005, 24, 269-292. [CrossRef]

11. Salager-Meyer, F. Discoursal flaws in medical English abstracts: A genre analysis per research and text type. Text 1990, 10, 365-384. [CrossRef]

12. Hyland, K. Disciplinary Discourses: Social Interactions in Academic Writing; University of Michigan Press: Ann Arbor, MI, USA, 2004.

13. Hyland, K.; Tse, P. Hooking the reader: A corpus study of evaluative that in abstracts. Engl. Specif. Purp. 2005, 24, 123-139. [CrossRef]

14. Amnuai, W.; Wannaruk, A. Investigating move structure of English applied linguistics research article discussions published in international and Thai journals. Engl. Lang. Teach. 2012, 6, 1-13. [CrossRef] 
15. Samar, R.G.; Talebzadeh, H.; Kiany, G.R.; Akbari, R. Moves and steps to sell a paper: A cross-cultural genre analysis of applied linguistics conference abstracts. Text Talk 2014, 34, 759-785. [CrossRef]

16. Tseng, F. Analyses of move structure and verb tense of research article abstracts in applied linguistics. Int. J. Engl. Linguist. 2011, 1, 27-39. [CrossRef]

17. Alharbi, L.M.; Swales, J.M. Arabic and English abstracts in bilingual language science journals: Same or different? Lang. Contrast 2011, 11, 69-85. [CrossRef]

18. Ghasemi, T.; Alavi, S.M. A comparative move analysis study of theses abstracts written by Iranian M.A. students of TEFL and English literature. Online Int. J. Arts Humanit. 2014, 3, 5-15. Available online: http:/ / onlineresearchjournals.org/IJAH/pdf/2014/feb/Ghasemi\%20and\%20Alavi.pdf (accessed on 18 September 2015).

19. Li, Q.; Pramoolsook, I. Research article abstracts in two subdisciplines of business: Move structure and hedging between management and marketing. Engl. Lang. Teach. 2014, 8, 52-63. [CrossRef]

20. Pho, P.D. Research article abstracts in applied linguistics and educational technology: A study of linguistic realizations of rhetorical structure and authorial stance. Discourse Stud. 2008, 10, 231-250.

21. Saeeaw, S.; Tangkiengsirisin, S. Rhetorical variation across research article abstracts in environmental science and applied linguistics. Engl. Lang. Teach. 2014, 7, 81-93. [CrossRef]

22. Min, H. A cross discipline comparison of tense choices in research abstracts. Engl. Teach. 2010, 65, 41-58.

23. Okamura, A.; Shaw, P. Development of academic journal abstracts in relation to the demands of stakeholders. In Abstracts in Academic Discourse: Variation and Change (Linguistic Insights), 1st ed.; Bondi, M., Lorés Sanz, R., Eds.; Peter Lang: Bern, Switzerland, 2014; pp. 287-318.

24. Dos Santos, M.B. The textual organization of research paper abstracts in Applied Linguistics. Text 1996, 16, 481-499. [CrossRef]

25. Suntara, W.; Usaha, S. Research article abstracts in two related disciplines: Rhetorical variation between linguistics and applied linguistics. Engl. Lang. Teach. 2013, 6, 84-99. [CrossRef]

26. Author Information Pack. Available online: http://www.elsevier.com/locate/esp (accessed on 1 July 2015).

27. Anthony, L. AntMover, Version 1.0.0; Computer Software; Waseda University: Tokyo, Japan, 2003; Available online: http:/ / www.laurenceanthony.net/ (accessed on 16 May 2015).

(C) 2016 by the authors; licensee MDPI, Basel, Switzerland. This article is an open access article distributed under the terms and conditions of the Creative Commons Attribution (CC-BY) license (http://creativecommons.org/licenses/by/4.0/). 